\title{
Cold Spray Metal-Ceramic Coatings using Satellited Powders
}

\author{
K. S. Al-Hamdani ${ }^{1,3}$, J.W. Murray², T. Hussain², A. Kennedy², A.T. Clare ${ }^{1}$ \\ Affiliations: ${ }^{1}$ Advanced component engineering laboratory (ACEL), University of Nottingham, \\ Nottingham NG7 2RD, UK \\ ${ }^{2}$ Advanced Materials Research Group, University of Nottingham, Nottingham NG7 \\ 2RD, UK \\ ${ }^{3}$ University of Thi-Qar, College of Engineering, 64001-Nasiriya, Iraq.
}

Keywords: Satelliting; Metal-ceramic; spray coatings; Titanium carbide; aluminium; cold spray

\begin{abstract}
A new preparation method was used to create a feedstock of pure Al powder to which a much finer TiC powder was attached. Cold spray (CS) coatings of pure Al, blended Al/TiC and satellited $\mathrm{Al} / \mathrm{TiC}$ were applied to an Al substrates. A seven-fold increase in TiC area fraction was measured in the satellited coating compared to that in the blended coating. Coating thickness also increased as a result of increased ceramic deposition. Crosssectional analysis revealed that the cohesion achieved between $\mathrm{Al}$ and $\mathrm{TiC}$, during satelliting process, survives the CS process, and is hence is demonstrated to be an effective method of producing ceramic-metal coatings.
\end{abstract}

\section{Introduction}

Ceramic-metal composite coatings are widely used to enhance the surface properties and performance of engineering components in the abrasive and corrosive environments [14]. There remains an industrial need to produce metal-ceramic coatings for aluminium components [5], where the high production cost of these composites is a significant barrier to their exploitation [6]. CS relies upon repeated high plastic deformation of incident particles to form a coating. CS coatings can be produced with low levels of porosity and oxidation [7]. However, low ductility materials (e. g. ceramics) are more difficult to deposit [8] since they can rebound when impacting substrate surfaces, resulting in a reduced deposition rate. Thus, brittle materials often need to be combined with more ductile materials for successful cold spraying [9]. It has been found that cold sprayed coating compositions are different to that of simply mixed feedstocks because the deposition efficiencies of the constituent powders are not the same at the same processing parameters [10]. In other words, this will lead to production of coatings with inhomegenous composition. To address this issue, various methods for delivering the soft matrix and hard reinforcing particles have been attempted [11]. Mechanically-alloyed, the two powders combine to offer a possible solution, but this has some drawbacks such as 
high processing cost, work hardening of the powder and heterogeneity of the reinforcement phase in the feedstock powder [12].

This study reports the use of a novel 'satelliting' approach [13] to creat a feedstock for CS coating. This is performed by using a polymer binder to attach fine ceramic particles onto relatively large metal particles. Satelliting has the advantages of a simple production procedure and no mechanical modification of the feedstock. The efficacy of this process is demonstrated by cold-spraying this feedstock and comparing the coating morphology and TiC fraction with an equivalent, blended powder.

\section{Experimental Methodology}

Commercially pure $\mathrm{Al}$, as the ductile matrix, and TiC powder, as the ceramic reinforcement, were "satellited" together to create a composite powder feedstock. The Al powder (Angang Group Aluminium Powder Ltd-China) has a spherical shape with $15-45 \mu \mathrm{m}$ size range (Figure 1-a). The angular TiC (GoodFellow-UK) has a particle size $<5 \mu \mathrm{m}$ with a $\mathrm{d}_{50}=1.5$ $\mu \mathrm{m}$, (Figure 1-b). The satelliting process involved-mixing the two powders (Al-12wt.\%TiC) in a tubular mixer for $20 \mathrm{~min}$. Simultaneously, a $2 \mathrm{wt} . \%$ binder, consisting of a $2.7 \mathrm{wt} . \%$ solution of poly-vinyl alcohol (PVA) in water, was sprayed during the mixing process. The powder mixture was then dried at $100^{\circ} \mathrm{C}$ for $12 \mathrm{~h}$. Scanning electron microscopy (SEM) was performed using a JEOL 6490LV, using back-scattered electron (BSE) and secondary electron (SE) imaging. A blended powder was also prepared by dry mixing the same fractions of TiC and Al. A comparison between the mixed and satellited powders can be seen in Figure 1-c and 1-d, where several Al powder particles are extensively covered in finer TiC particles.
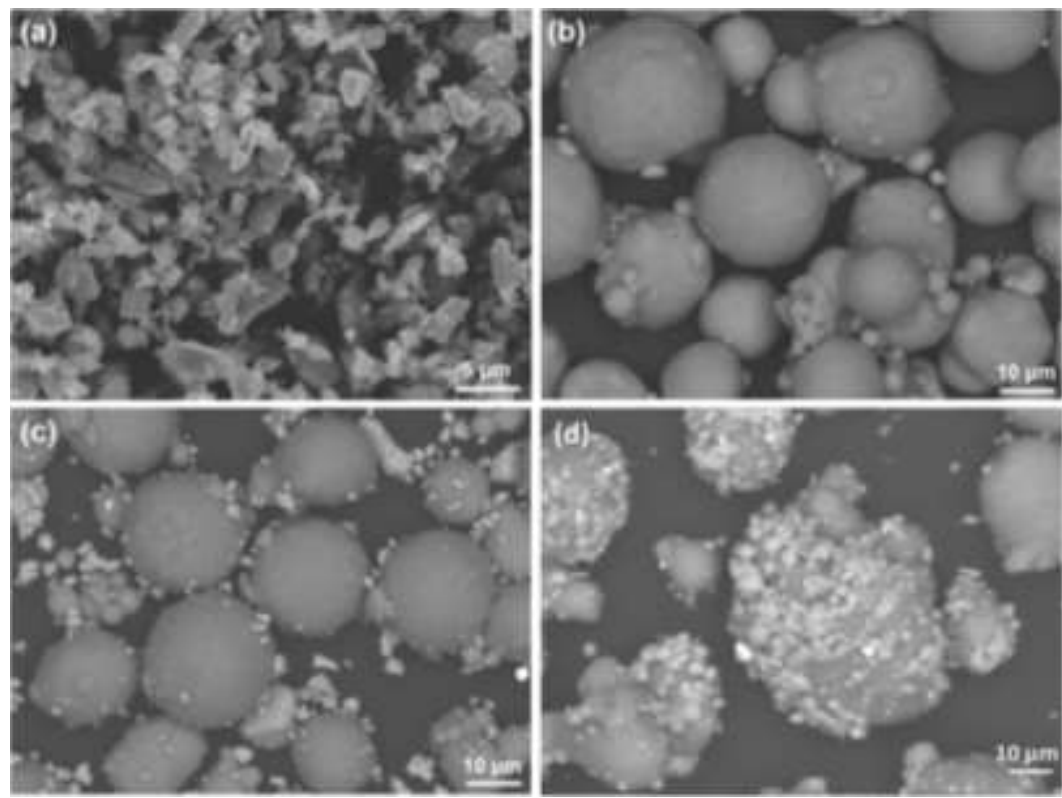
Figure 1 SEM images showing the morphology of (a) virgin TiC powder, (b) virgin Al powder, (c) simply blended powder $(\mathrm{Al} / \mathrm{TiC})$, and $(\mathrm{d})$ satellited powder $(\mathrm{Al} / \mathrm{TiC})$ revealing several fully coated particles.

$6 \times 25 \times 50 \mathrm{~mm}$, Al 6068-T6 material was used as the substrate. The full details and set up procedure for the CS apparatus used is described elsewhere [14]. The main parameters used in the CS experiments were kept constant for all material types and were as follows; traverse speed, $60 \mathrm{~mm} / \mathrm{s}$, powder mass flow rate $12.4 \mathrm{~g} / \mathrm{min}$, stagnation pressure of the main and carrier gas, 28 and 29 bar, respectively. Fast-scanning using a single pass at $800 \mathrm{~mm} / \mathrm{s}$ was also used to produce individual deposits from pure Al, blended Al -12 wt.\% TiC and satellited $\mathrm{Al}-12 \mathrm{wt} . \% \mathrm{TiC}$.
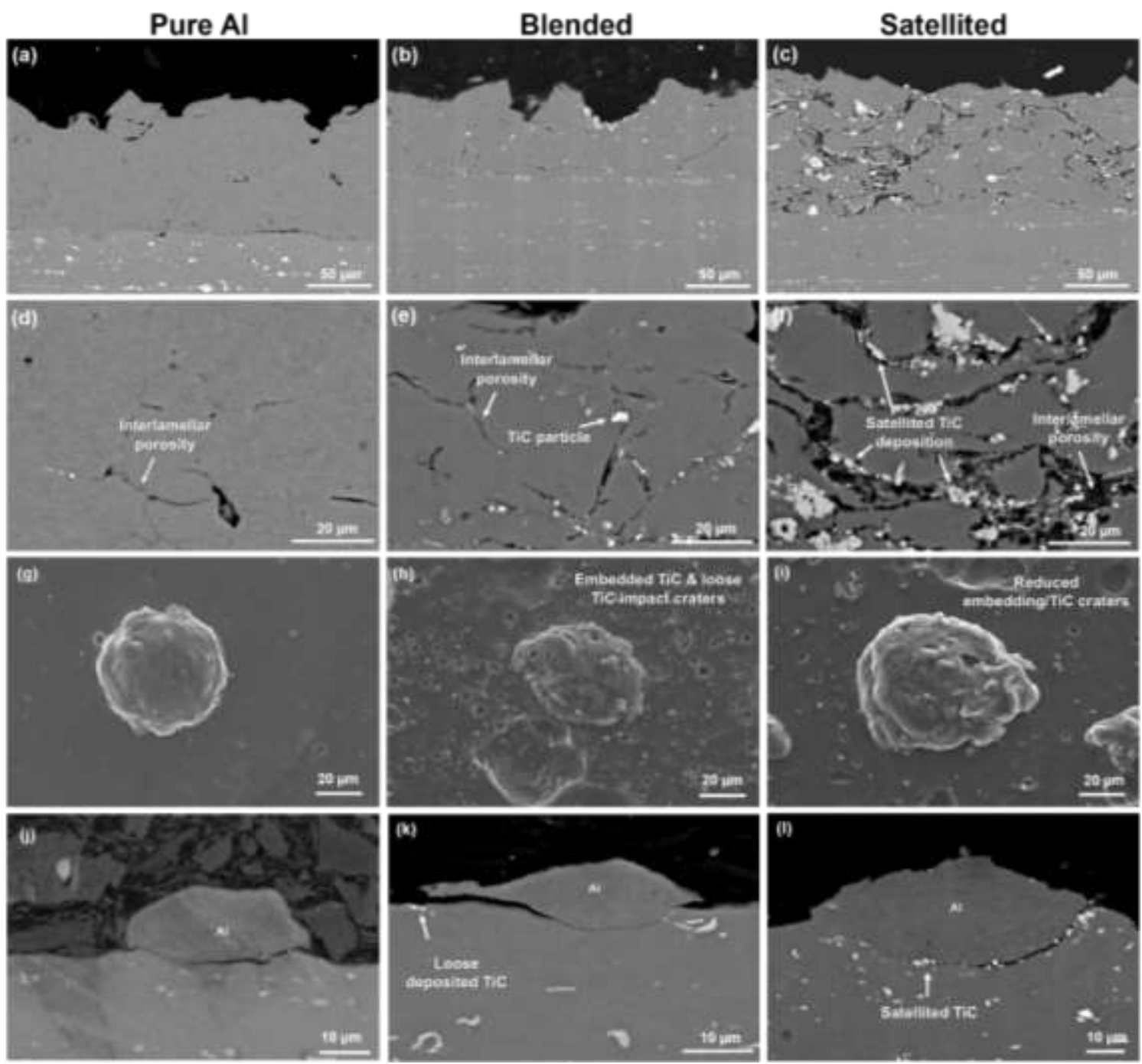

Figure 2 Cross-sectional BSE images at two magnifications and high magnification SEM images of individual deposited particles showing the different structures of the cold sprayed coatings and particle/surface deformation of different feedstocks; (left column ) pure Al, (middle column) blended, and (right column) satellited. 


\section{Results and discussion}

Figure 2 shows cross-sectional BSE SEM images of the deposited coatings, with higher magnification in the second row ( $d$, e and $f$ ). Moreover, top and cross-sectional views of individual deposited particles of the related feedstocks are also presented in the third and fourth rows, respectively. From these images it is apparent that both interlamellar porosity, as well as the level of TiC deposition, are increased for the satellited coating. In addition, TiC particles can be clearly seen at splat boundaries, and this allows TiC particles to follow the distribution of the parent, Al, powder particles. It is observed, as a result of the adhesion between the two powders, that there is a clear improvement in ceramic distribution over coatings. Image processing software (Image-J) was used to quantify the difference in porosity, TiC deposition, and coating thickness for the coating types. Three $260 \times 195 \mu \mathrm{m}$ representative images of each deposit were analysed and the average values were considered. Figure 3 (a) shows the TiC area fraction in both composite coatings, measured from the cross-section, showing a seven-fold increase in mean area fraction for the satellite powder coating compared to the coating made from simply-blended powder.

a)

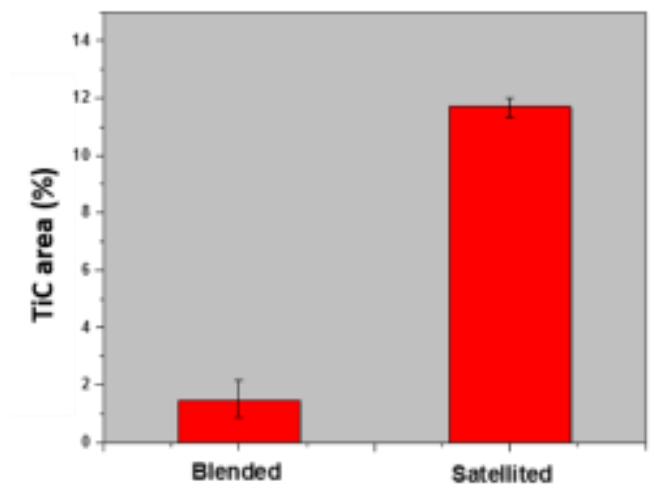

b)

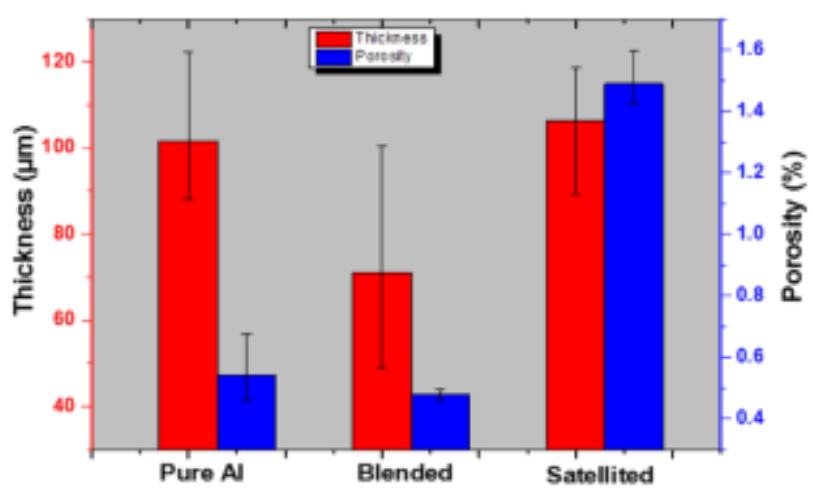

Figure 3 (a) The TiC area fraction in the different composite coatings, (b) the average thickness and the percentage areal porosity for the coatings. Error bars represent the maximum and minimum range of the values measured.

Figure 3 (b) shows the thickness and porosity measurements for the three coating types. A slight decrease in the coating thickness for the blended powder was measured, in comparison with both the Al and satellited coatings. However, this coating was nonuniform in thickness, reaching an approximate minimum of $50 \mu \mathrm{m}$ and maximum of 100 $\mu \mathrm{m}$. The pure Al and satellited coatings had a similar thickness, of just over $100 \mu \mathrm{m}$, and also a similar range of thicknesses and hence process repeatability is shown to be improved. 
Figure 3 (b) also shows the porosity levels of the deposited coatings. Generally, the coldsprayed particles undergo two stages of deformations. The first is the high strain rate deformation of the particle with another particle or the substrate during bonding and the second stage of deformation is the further reduction in porosity due to tamping effect of succesive incoming particles on top of the bonded particle [15]. Thus, any lack of deformation at any side of a particle will most likely lead to the generation of microporosity. This may be reduced by exploiting higher velocity apparatus. Results confirm that the satellited coating has a higher level of porosity $(\sim 1.5 \%)$, compared with the other coatings. This is mostly likely due to the high presence of ceramic at the splat boundaries, where the hard phase hinders splat deformation from all sides. With regard to the blended coating, the larger fraction of $\mathrm{Al}$ particles and their large size provide deformable areas around TiC particles which reduces the porosity in these coatings. A similar trend was observed by Guo, et al. [16] where individual ceramic particles were shown to be surrounded by metal splats in cold-sprayed composite coatings.

From the observation of the TiC area fraction in the coatings, it can be concluded that the use of satellited powder has facilitated ceramic particles becoming embedded within the deposited coating. This has been achieved by the elimination of non-ductile particles rebounding during cold spraying. To help elucidate the difference in deposition mechanisms for the coating types, individual particle analysis was conducted in both planar and perpendicular to the spray direction cross-sections. In Figure 2 (g)-(i), individual, deposited Al particles can be seen on a polished Al substrate. Of note is the substantially reduced cratering and embedding of $\mathrm{TiC}$ in areas peripheral to the Al particle in the case of the satellited powder. An average of a $74 \%$ reduction in the number of TiC craters in the deposits-free areas of the substrate surface was measured. This indicates that the satellited powder constituents were maintained combined throughout the spraying process. Figure $2(\mathrm{j})-(\mathrm{I})$ shows cross-sections of particles deposited from the three feedstocks. In the cross-section of the coating produced from blended feedstock, a deformed, deposited particle can be seen, with loose TiC deposited separately in the vicinity of the particle. For the cross-section of the satellited particle, TiC particles can be seen embedded beneath the deformed particle, and a slightly increased interlamellar porosity can be seen as a result. Significantly fewer TiC particles can be seen on top of the deposited satellited particles, most likely due to them becoming detached as a result of impact stresses of the satellite particles.

Figure 4 illustrates the proposed mechanisms for the cold-spray deposition process using blended and satellited powders containing a small, hard particle and a large, more compliant parent particle. In the case of the blended feedstock, the majority of TiC particles arrive separately from the large Al particles and predominantly rebound from the 
substrate surface after undergoing almost no deformation. The relatively large range of thickness yielded by the blended powder can be explained by the inhomogeneity of the feedstock. A small number of scattered TiC particles remain embedded, but are insufficient to form a homogeneous coating.

It is suggested that the satellite is robust enough to survive mechanical agitation during cold spray process starting from the powder feeder and through the gun, down to the substrate surface. Accordingly, a high proportion of ceramic which was attached to the satellited powder will be embedded in the coating, which explains the high presence of ceramic in the associated coating. It is proposed that upon impact with the soft substrate, particles underneath the incident particles are embedded at the interface between splats. Therefore, the amount of TiC on the top coating surface will be lower than that inside, as they are not consolidated by the following layer. Consequently, further surface processing (e.g. machining) may be needed to expose more TiC to create a wear resistant surface for the composite coating. An increase in porosity was observed in the satellited coating, while the more evenly distributed TiC in the satellited feedstock, and subsequent more steady flow during spraying, explains the smaller variation in thickness of its associated coating.

(a)

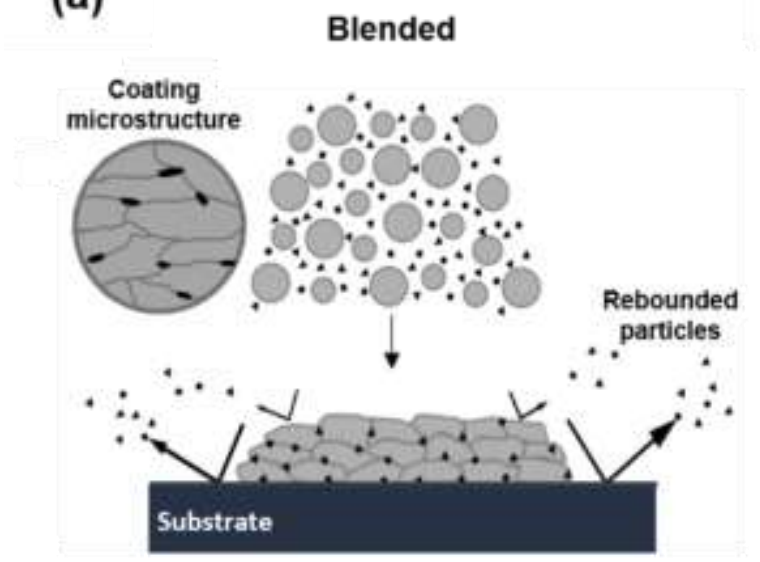

(b)

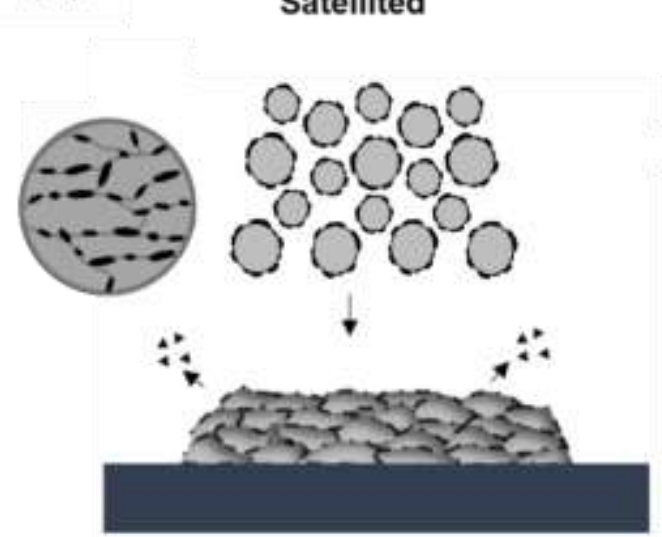

Figure 4 Schematic diagrams for two coating mechanisms using: (a) blended feedstock, (b) satellited feedstock.

\section{Conclusions}

By using a novel preparation method to bond hard TiC particles to larger Al particles, a composite feedstock has been produced which shows a significant improvement in yield of TiC embedded in coatings produced by cold spraying. This novel approach has much wider applications to the production of multi-component coatings via a wide range of processes. 


\section{Acknowledgements}

The authors would like to thank for financial support the Iraqi ministry of higher education and EPSRC (Grant No EP/L017121/1 "High Value Manufacturing Catapult Fellowship Centre"). They would also like to thank Mr. Rory Screaton for the technical support throughout Cold-Spray experiments undertaken for this work.

\section{References}

[1] C. Selcuk, A.R. Kennedy, Materials Letters, 60 (2006) 3364-3366.

[2] M. Rosso, Journal of Materials Processing Technology, 175 (2006) 364-375.

[3] L. Wang, Y. Gao, Q. Xue, H. Liu, T. Xu, Materials Science and Engineering: A, 390 (2005) 313-318.

[4] E. Huttunen-Saarivirta, Journal of Alloys and Compounds, 363 (2004) 154-178.

[5] R. Shyu, C. Ho, Journal of materials processing technology, 171 (2006) 411-416.

[6] V. Senthilkumar, B.U. Omprakash, Journal of Manufacturing Processes, 13 (2011) 6066.

[7] G. Rolland, P. Sallamand, V. Guipont, M. Jeandin, E. Boller, C. Bourda, Journal of thermal spray technology, 21 (2012) 758-772.

[8] T.Y. Hussain, S. and Li, C.-J., in, Springer, London, 2015.

[9] A. Moridi, S. Hassani-Gangaraj, M. Guagliano, M. Dao, Surface Engineering, 30 (2014) 369-395.

[10] R. Maestracci, A. Sova, M. Jeandin, J.-M. Malhaire, I. Movchan, P. Bertrand, I. Smurov, Surface and Coatings Technology, 287 (2016) 1-8.

[11] C. Feng, V. Guipont, M. Jeandin, O. Amsellem, F. Pauchet, R. Saenger, S. Bucher, C. Iacob, Journal of thermal spray technology, 21 (2012) 561-570.

[12] C. Suryanarayana, International Materials Reviews, 40 (1995) 41-64.

[13] A. Clare, A. Kennedy, in, Google Patents, 2014.

[14] T. Hussain, D. McCartney, P. Shipway, Surface and Coatings Technology, 205 (2011) 5021-5027.

[15] Y. Tao, T. Xiong, C. Sun, H. Jin, H. Du, T. Li, Applied Surface Science, 256 (2009) 261-266.

[16] X. Guo, J. Chen, H. Yu, H. Liao, C. Coddet, Surface and Coatings Technology, 268 (2015) 94-98. 